\title{
Gravity, Bilateral Agreements, and Trade DivERSION IN THE AMERICAS*
}

\author{
RAYMOND ROBERTSON \\ Macalester College \\ ANTONI EsTEVADEORDAL \\ Inter-American Development Bank
}

Krishna (1998) shows that a bilateral agreement between two countries render a multilateral agreement less attractive if the bilateral agreement is trade diverting. This paper combines Krishna's model with the empirical approach of Anderson and van Wincoop (2003) to show that the estimated effect of tariffs in a multiple country $(n>3)$ context over time measures trade diversion. We apply this measure to new asymmetric, time-varying Latin American trade and tariff data using Anderson and van Wincoop's (2003) nonlinear estimation approach and OLS. The results show an increase in trade diversion as sub-regional trade agreements proliferated and enthusiasm for the Free Trade Agreement of the Americas declined.

\section{JEL: F02, F13, F15}

Keywords: Gravity Models, Asymmetric Tariffs, Trade Diversion

\section{INTRODUCTION}

The 2005 Summit of the Americas adjourned without setting a date for further negotiations for the Free Trade Agreement of the Americas (FTAA). While the FTAA may be resurrected, it is clear that enthusiasm for the agreement has declined precipitously from 1995, when the FTAA negotiations began. At the same time, bilateral agreements have proliferated throughout the Americas, raising the

\footnotetext{
* The authors thank James Anderson, Scott Baier, David Hummels, and the anonymous referees for very helpful discussions and Eric van Wincoop for sharing programs and data. The authors are solely responsible for the content of the paper, and the ideas expressed herein do not necessarily reflect those of the Inter-American Development Bank. The authors thank Colin Hottman for excellent research assistance.

Email: robertson@macalester.edu
} 
possibility that bilateral agreements are stumbling blocks for multilateral accords ${ }^{1}$. The question of whether bilateral agreements are "building blocks" or "stumbling blocks" remains at the heart of the integration policy debate, and theory suggests that one key difference between these two outcomes is trade diversion: the degree to which bilateral agreements hinder multilateral negotiations depends on the extent of trade diversion created by the bilateral agreements. Unfortunately, there are few (if any) effective and practical measures of trade diversion in the multicountry context.

Measuring trade diversion is important for policy for two reasons. First, as noted above, trade diversion makes multilateral agreements less attractive. Second, trade diversion is generally considered to be a risk of bilateral agreements because it is economically inefficient. Multilateral agreements avoid this inefficiency, making the policy choice between bilateral and multilateral agreements both relevant and dependent on being able to measure trade diversion.

Our paper makes two main contributions. The first is a measure of trade diversion that can easily be applied to the multi-country context. We begin with Krishna's (1998) theoretical political economy model, which suggests that bilateral agreements can reduce the incentives to pursue multilateral negotiations in the presence of trade diversion. Implicit in his model is a metric for trade diversion that can be empirically applied to a multi-country environment by adapting Anderson (1979) and Anderson and van Wincoop (2003, henceforth AW). AW shows the importance of "multilateral resistance" measures in empirical studies. Trade between two countries, after controlling by size and other variables, is decreasing in their bilateral trade barrier relative to the average barrier of the two countries to trade with all their partners. While AW focus on the omitted variable bias that comes from ignoring multilateral resistance, we show that incorporating multilateral resistance can generate an alternative empirical metric for trade diversion that matches Krishna's (1998) framework.

Our second contribution is the application of this approach to a new and unique data set on tariff rates. Studies of trade diversion have traditionally focused on discrete events, such as the entry into force of a trade agreement ${ }^{2}$. Rose (2004), in particular, finds that the World Trade Organization (WTO) has had very little, if any, effect on trade other than that generated from tariff changes. These results suggest that focusing on tariffs is a more appropriate way to focus on the effects of trade agreements.

Relatively few, however, have attempted to analyze the effects of preferential trade liberalization because the data requirements are considerable. To get the appropriate tariff data, one must examine each preferential trade agreement and record the tariff phase-in schedule, which is how we constructed the data used in this paper.

\footnotetext{
1 For examples of this debate, see Ethier (1998a, 1998b) and Krueger (1995).

2 Prominent examples include Romalis (2001), who focuses on NAFTA, and Rose (2004), who focuses on the WTO.
} 
We ground our empirical work by explicitly incorporating asymmetric tariff barriers into the familiar gravity model, following some recent empirical attempts to directly measure trade costs (Hummels, 2001a; Limao and Venables, 2001). Our data allow us to take advantage of the asymmetric nature of preferential tariffs among members of a preferential trade area in order to employ and enhance AW's non-linear estimation approach. Baier and Bergstrand (2005), however, suggest that the OLS estimates are sufficient. We therefore use both approaches. The AW results have a smaller variance over time than the OLS estimates, but both approaches suggest rising trade diversion.

Combining these theoretic advances with a newly-constructed data set generates an approach that is intuitively straightforward. Falling average tariffs, such as through pursuing certain bilateral agreements, increases the trade-reducing effect of the remaining tariffs. Ceterus paribus, a bilateral agreement increases the difference between a country's average tariff and the remaining tariffs. The trade diversion that drives Krishna's (1998) model emerges as an increasingly negative estimated effect of remaining tariffs. That is, the remaining tariffs appear to become more effective at blocking trade as the bilateral agreement diverts trade from the pairs outside the agreements.

The Latin American experience between 1985 and 1997 provides an excellent opportunity to evaluate the link between bilateralism and multilateralism for two main reasons. First, negotiations for the Free Trade Agreement of the Americas, expected to have been completed in 2005, have bogged down. Simultaneous negotiations for bilateral agreements have been generating what has come to be known as the "spaghetti bowl" of bilateral agreements and reductions in preferential tariff rates. In few places has the question of whether bilateral agreements hinder or help multilateral trade negotiations been as relevant for policy as in Latin America over the last 15 years. Second, concentrating on a geographically defined region allows us to focus on the tariff effects and abstract somewhat from the multilateral resistance effects of distance.

Finally, having asymmetric tariff rates offers us the chance to make two additional contributions. First, while the majority of the literature uses average tariff rates under the assumption that tariff rates are basically symmetric, we show that, while trade flows are generally symmetric, tariff rates generally are not. Second, employing asymmetric tariffs also allows us to estimate the elasticity of substitution of goods between countries - a critical, but rarely estimated, parameter in many theoretic trade models.

Our study unfolds in six remaining sections. In Section 2 we present our data, discuss trade liberalization in the Americas, and highlight the importance of asymmetry in tariff data. In Section 3 we show how we combine Krishna and AW's theoretic approaches. In Section 4 we describe our estimation approach. Section 5 contains our results and we explore robustness in Section 6 before concluding in the final section. 


\section{Data ANd Stylized Facts}

\subsection{Summary Statistics}

The major data collection effort of this paper involved constructing the preferential bilateral tariff rates for all possible bilateral relations among the 29 countries included in our sample from original sources, in addition to the mostfavoured-nations (MFN) rates that each country applies to the rest of the world. The dataset used in this study covers the period from 1985 to 1997 and the following countries: Argentina, Bolivia, Brazil, Colombia, Chile, Ecuador, Mexico, Paraguay, Peru, Uruguay, Venezuela, Japan, the United States, Canada, and the European Union. The standard gravity variables come from standard sources in the gravity literature, and in particular from Andrew Rose's website. We have complemented these data with trade data from United Nations COMTRADE database. All MFN tariff data have been collected from official national statistical sources and regional integration secretariats. All preferential tariff data have been collected directly from original tariff schedules from regional and bilateral trade agreements (reciprocal and non-reciprocal) signed and implemented during the period under study. It includes bilateral and regional agreements signed under the Latin American Integration Association (LAIA) framework; NAFTA agreement and other non-reciprocal agreements with the United States and the European Union.

Table 1 contains the list of countries included in the data and some summary statistics. Several features deserve mention. As the list of countries shows, we focus on Latin America but include Canada, the United States, Europe, and Japan. The data exhibit the typical gravity model data characteristics in the sense that larger and closer countries trade more. Table 1 contains the average ad-valorem tariff rate, but we use $\log (1+$ tariff $)$, -in which a $10 \%$ tariff would be 0.10 - in our estimation. Due to our sample period, the tariff rates European countries have for each other and impose on non-European countries are identical for all countries within the European Union. We discuss the evolution of tariffs in Latin America in the next section.

\subsection{Trade Liberalization in the Americas}

Between 1985 and 1997, bilateral and sub-regional trade agreements proliferated throughout the Americas. Figure 1 illustrates what is now known as the "Spaghetti Bowl" of regional trade agreements. These agreements were often accompanied by unilateral trade liberalization. Our data cover this period of liberalization and the phase-in period. The data from our sample show falling simple average tariff rates (Figure 2). The decline begins in 1985. Average tariffs fall dramatically during the 1989-1991 period before leveling out around 1993. This decline in simple average tariffs reflects falling MFN tariff levels as well as falling preferential tariffs incorporated in bilateral agreements. Figure 3 shows the MFN tariff rates separately from the preferential tariff rates. The proliferation of bilateral agreements and falling average tariffs is evident in Figures 2 and 3. 
TABLE 1

SUMMARY STATISTICS

\begin{tabular}{lrrrrr}
\hline Exporting Country & $\begin{array}{c}\text { Mean } \\
\text { Log Trade }\end{array}$ & $\begin{array}{c}\text { Mean } \\
\text { Log GDP }\end{array}$ & $\begin{array}{r}\text { Mean } \\
\text { Tariff }\end{array}$ & $\begin{array}{r}\text { St. Dev. } \\
\text { Tariff }\end{array}$ & $\begin{array}{c}\text { Mean } \\
\text { Distance }\end{array}$ \\
\hline Argentina & 4.988 & 12.165 & 11.508 & 11.412 & 5219.30 \\
Austria & 5.069 & 12.084 & 9.796 & 14.573 & 3599.89 \\
Bel-Lux & 6.213 & 12.317 & 9.796 & 14.573 & 3319.59 \\
Bolivia & 1.336 & 8.700 & 11.057 & 10.966 & 4589.30 \\
Brazil & 6.259 & 13.121 & 11.281 & 10.659 & 4396.56 \\
Canada & 5.598 & 13.289 & 13.041 & 12.644 & 3859.19 \\
Chile & 4.777 & 10.610 & 11.603 & 11.221 & 5362.56 \\
Colombia & 4.254 & 11.011 & 11.251 & 10.923 & 4162.59 \\
Germany & 7.969 & 14.376 & 9.796 & 14.573 & 3514.26 \\
Denmark & 5.269 & 11.879 & 9.796 & 14.573 & 3531.74 \\
Ecuador & 2.486 & 9.644 & 10.794 & 10.238 & 4355.15 \\
Spain & 6.219 & 13.101 & 9.796 & 14.573 & 3310.81 \\
Finland & 4.886 & 11.674 & 9.796 & 14.573 & 3923.52 \\
France & 7.166 & 14.059 & 9.796 & 14.573 & 3923.52 \\
Great Briton & 7.104 & 13.840 & 9.796 & 14.573 & 3280.93 \\
Greece & 3.139 & 11.445 & 9.796 & 14.573 & 4016.96 \\
Ireland & 4.737 & 10.854 & 9.796 & 14.573 & 3286.33 \\
Italy & 7.081 & 13.874 & 9.796 & 14.573 & 3577.70 \\
Japan & 7.212 & 15.124 & 13.112 & 12.615 & 7606.15 \\
Mexico & 4.731 & 12.611 & 11.854 & 11.577 & 4741.56 \\
Netherlands & 6.457 & 12.688 & 9.796 & 14.573 & 3340.37 \\
Peru & 3.600 & 10.429 & 11.565 & 9.880 & 4664.74 \\
Portugal & 4.209 & 11.250 & 9.796 & 14.573 & 3296.30 \\
Paraguay & 1.219 & 8.787 & 11.025 & 10.943 & 4786.59 \\
Sweden & 5.935 & 12.342 & 9.796 & 14.573 & 3733.96 \\
Uruguay & 2.675 & 9.445 & 11.171 & 10.836 & 5212.52 \\
United States & 8.179 & 15.731 & 13.076 & 12.642 & 3880.63 \\
Venezuela & 4.016 & 11.137 & 11.474 & 11.350 & 3885.44 \\
\hline & & & & & \\
\hline
\end{tabular}

Notes: Trade and Gross Domestic Product (GDP) are measured in U.S. dollars. The tariff is the average ad valorem tariff rate, and the standard deviation (St. Dev.) of the tariff rate is over time and country. These averages are over all countries and all years 1985-1997. Distance is measured in kilometers. Source: Inter-American Development Bank based on official national sources.

Bilateral and sub-regional agreements are, by definition, exclusive. The result of these agreements that differs from multilateral agreements is that the difference between the maximum tariff and the mean tariff rises with bilateral agreements. If multilateral resistance matters, then this suggests that, effectively, the remaining tariffs (for countries not included in the agreement) effectively rise (relative to the mean). This is exactly what happened in the Americas, as shown in Figure 4. Figure 4 shows both the standard deviation of importer tariff rates and the average difference between the mean and maximum tariff. Both rise as the mean tariff falls. The multilateral resistance concept, as described by the theory 


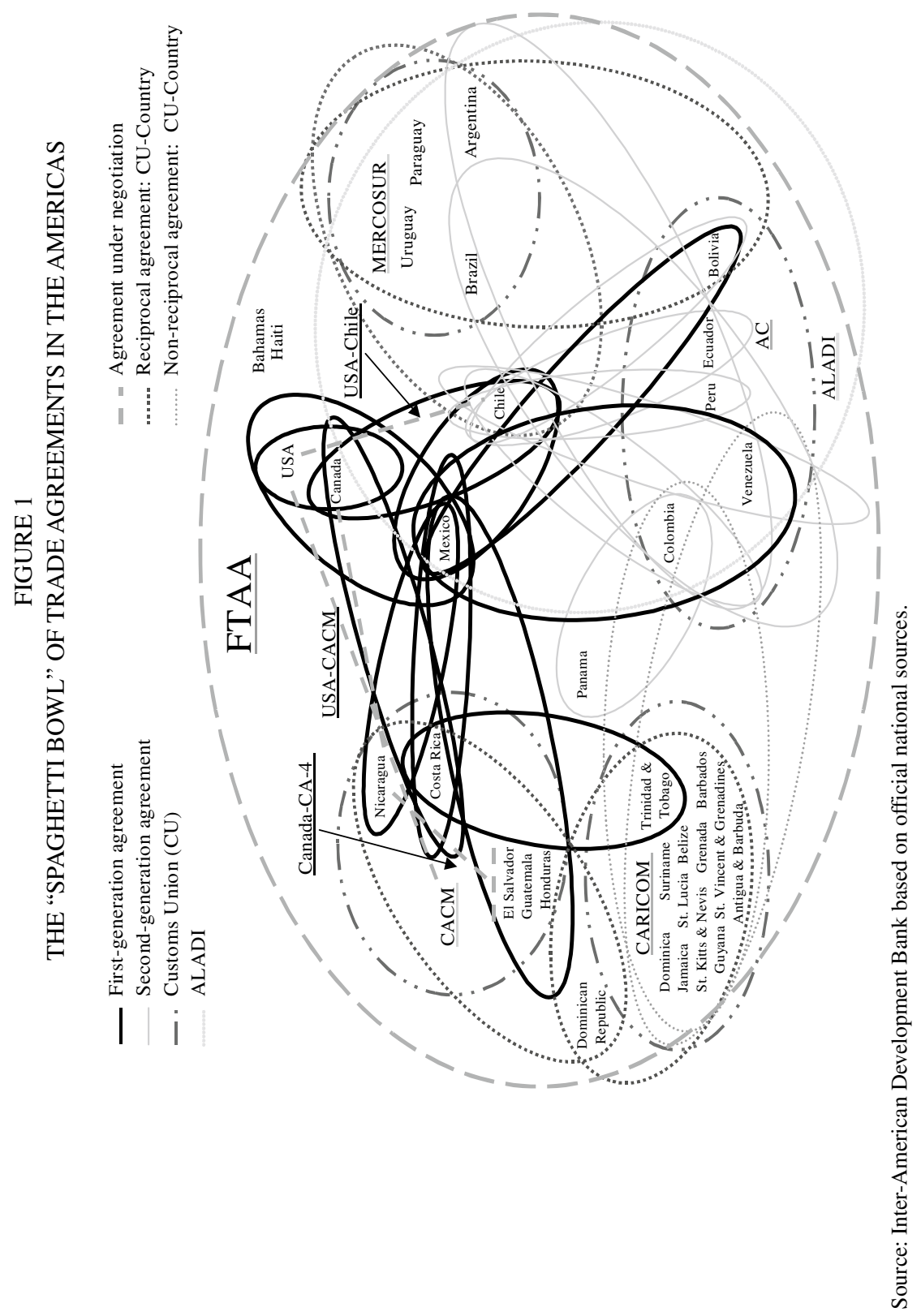


FIGURE 2

SIMPLE AVERAGE TARIFF RATES

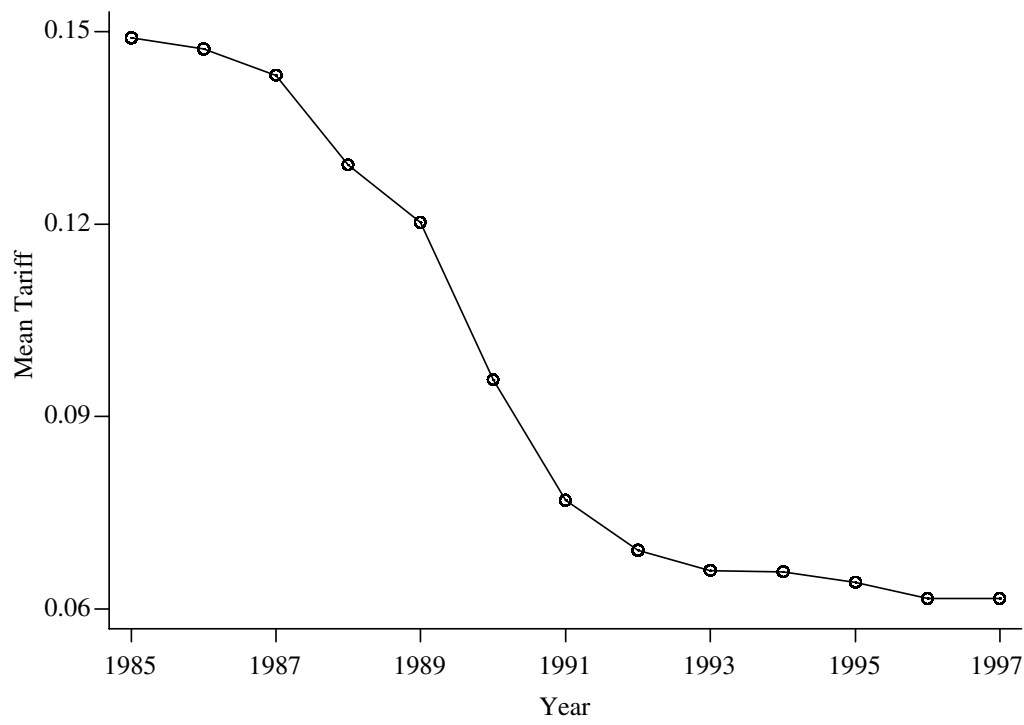

Notes: This figure shows the simple (unweighted) annual average of the log of the tariff rate plus one in the data used in the empirical work.

Source: Inter-American Development Bank based on official national sources.

FIGURE 3

PREFERENTIAL AND MFN TARIFF RATES IN LATIN AMERICA

(Percent)

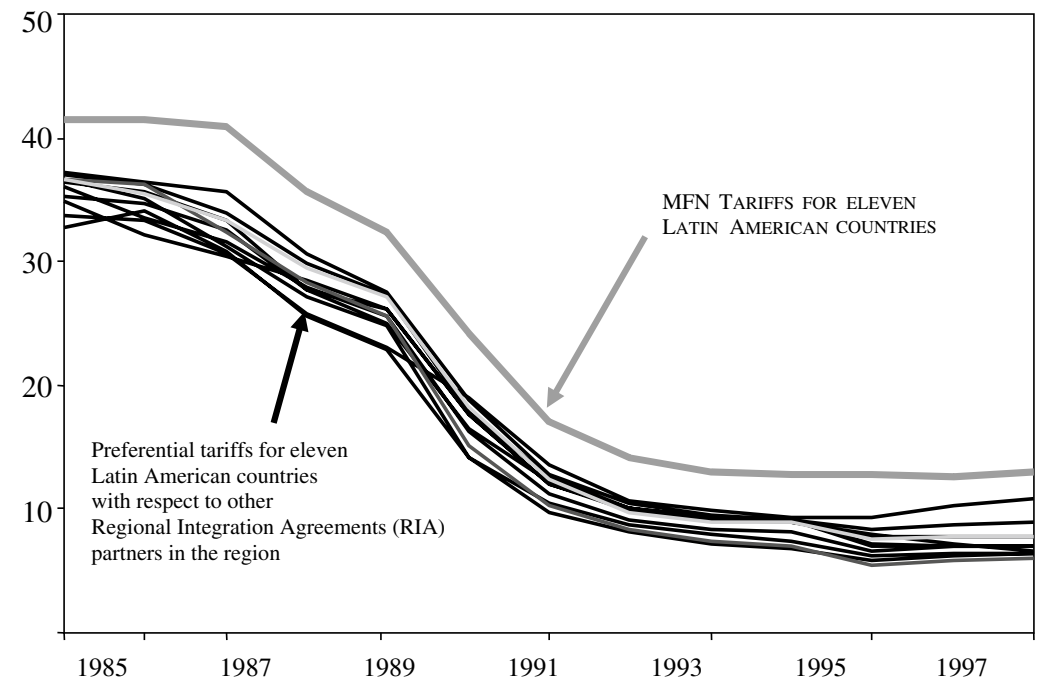

Note: The countries included are Argentina, Bolivia, Brazil, Chile, Colombia, Ecuador, Mexico, Paraguay, Peru, Uruguay and Venezuela. Calculations include only ad valorem tariffs. Source: Inter-American Development Bank based on official national sources. 
FIGURE 4

\section{TARIFF DISPERSION}

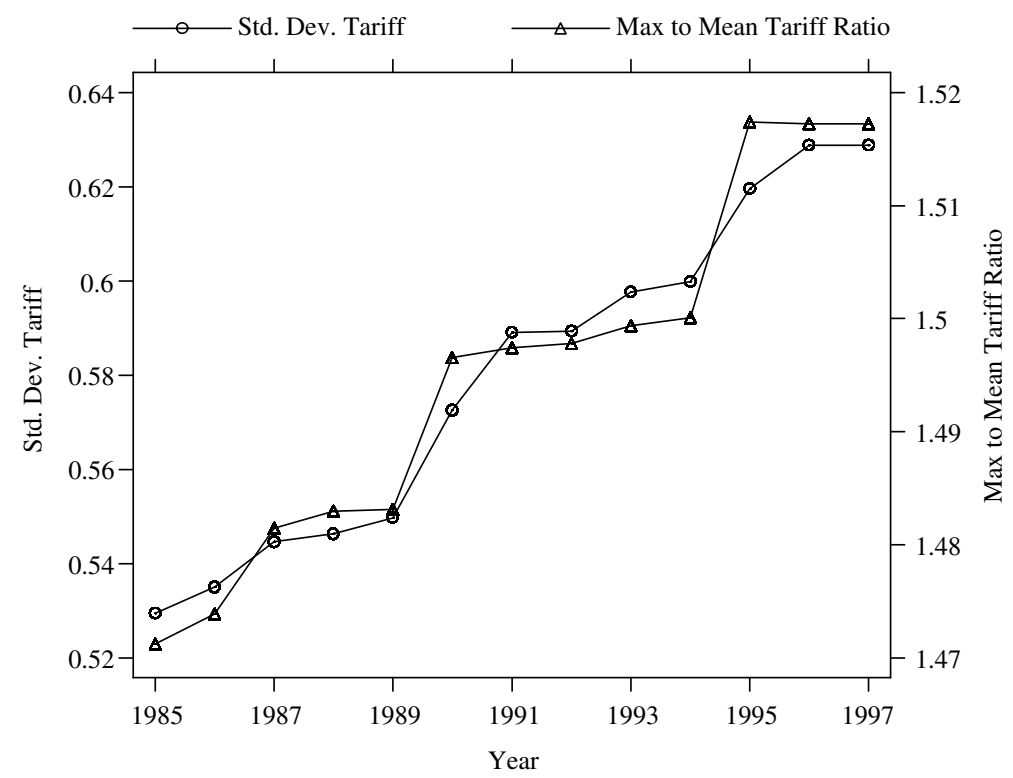

Notes: The standard deviation line graphs the annual average of the standard deviation of the $\log$ of one plus the tariff rate within importing countries. The "Max to Mean" ratio graphs the annual average of the maximum tariff divided by the mean tariff within importing countries.

Source: Inter-American Development Bank based on official national sources.

above, suggests that the rising difference between average tariffs and the maximum tariff also affects trade between an importer and the country facing the maximum tariff - even if the maximum tariff does not change.

\subsection{Asymmetry}

One contribution of this paper is that it incorporates asymmetric tariff variables. Trade patterns are generally symmetric: countries that export a lot to a partner generally import a lot from that partner. This is true for our entire sample. Figure 5 illustrates this pattern for 1997 with a graph of country $i$ 's exports and trade partner country $j$ 's exports. The resulting coefficient (standard error) of the implied simple regression is $0.904(0.025)$ with an adjusted $\mathrm{R}^{2}$ of 0.784 . One country's exports to a given partner explain about $80 \%$ of the variation of partner exports to the first country. This graph indicates that total trade is a very good proxy for unilateral trade.

Tariffs, in contrast, are generally not symmetric. Figure 6 illustrates this point for 1997 in which one country's tariffs explain less than $40 \%$ of the variation 
FIGURE 5

THE SYMMETRY OF TRADE

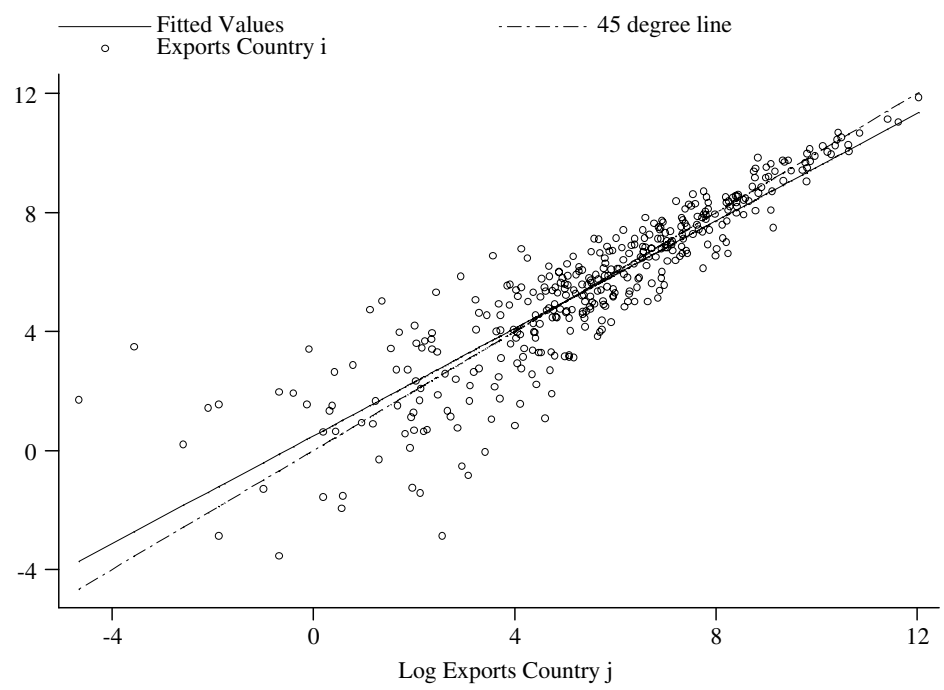

Notes: The y-axis measures the log of exports for country j's trading partner for 1997. The fitted values line is the predicted value of an OLS regression of the exports of country $i$ on country $j$ 's exports. The resulting coefficient (standard error) of that regression is $0.904(0.025)$ with an adjusted $\mathrm{R}^{2}$ of 0.784 .

Source: Inter-American Development Bank based on official national sources.

in their partner's tariffs towards them ${ }^{3}$. The symmetry of tariffs increases over our sample. Prior to 1990, one country's tariffs explain less than $1 \%$ of the variation in the partner's tariffs.

The implication of this asymmetry is that average trade barriers introduce possibly significant measurement error when they are used as proxies for partnerspecific tariffs. This measurement error would result in attenuation bias, biasing the estimated effects of tariffs towards zero, suggesting that the literature that relies on average tariffs underestimates the real impact of tariffs. This result also highlights the importance of asymmetric tariffs. As the theory in the next section shows, the estimated effect of these asymmetric tariffs measures trade diversion.

\section{THEORY}

Krishna (1998) employs a Cournot model to show that a bilateral agreement between two countries can make liberalizing with a third country (forming a multilateral agreement) less attractive if the bilateral agreement is trade diverting.

3 The resulting coefficient (standard error) of the tariff regression is $0.616(0.040)$ with an adjusted $\mathrm{R}^{2}$ of 0.390 . 


\section{FIGURE 6 \\ THE ASYMMETRY OF TARIFFS}

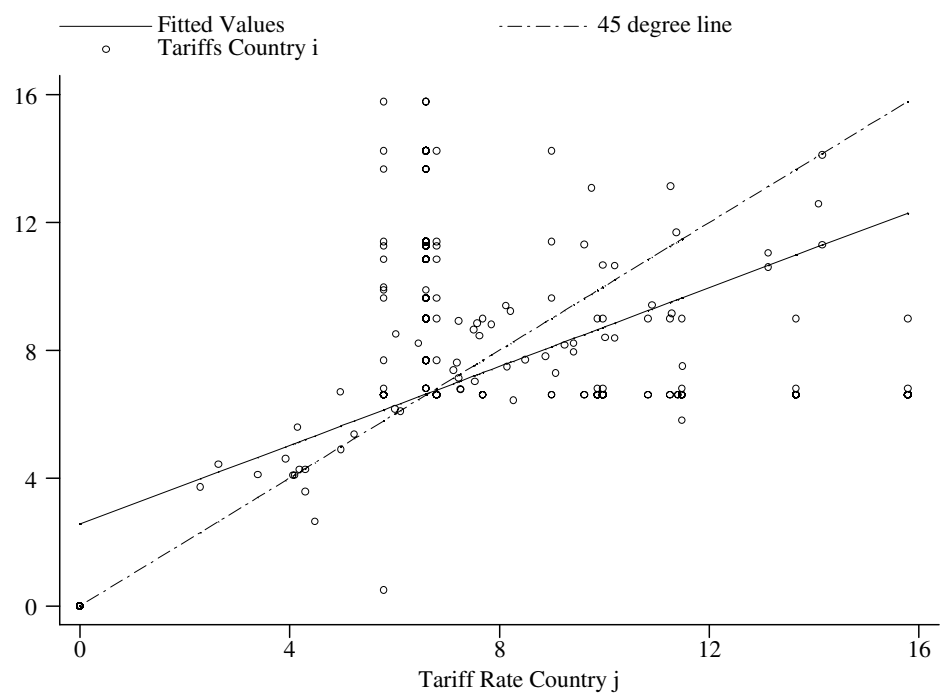

Notes: The $\mathrm{x}$-axis (y-axis) measures the $\log$ of one plus the tariff rate for country $j$ (country $i$, country $j$ 's trading partner) for 1997 . The fitted values line is the predicted value of an OLS regression of the log of one plus the tariff rate of country $i$ on the $\log$ of one plus country $j$ 's tariff rate. The resulting coefficient (standard error) of that regression is $0.616(0.040)$ with an adjusted $R^{2}$ of 0.390 .

Source: Inter-American Development Bank based on official national sources.

One of AW's main insights is that the concept of "multilateral resistance" affects trade patterns. In this section, we combine these contributions to illustrate how the "multilateral resistance" concept can be applied to Krishna's basic approach to generate a metric of trade diversion.

We begin with the simplest form of a Cournot model ${ }^{4}$. Consider three countries, 1,2 , and 3. Defining exports from country $i$ as $\mathrm{q}_{i}$ and the constant marginal production cost in country $i$ as $g_{i}$, assume that 2's demand for imports is simple and linear: $P=1-Q$ in which $Q=q_{1}+q_{3}$. The Cournot solution for 2's demand for imports from each country is then

$$
\begin{aligned}
& q_{1}=\frac{1-2 g_{1}+g_{3}}{3} \\
& q_{3}=\frac{1-2 g_{3}+g_{1}}{3}
\end{aligned}
$$

4 Since this presentation is simply illustrative, we assume homogeneous goods, zero transportation costs, and benevolent governments, and abstract almost entirely from the consumption side and domestic production. 


\section{FIGURE 7}

\section{CROSS-TARIFF EFFECTS IN A SIMPLE 3-COUNTRY COURNOT MODEL}

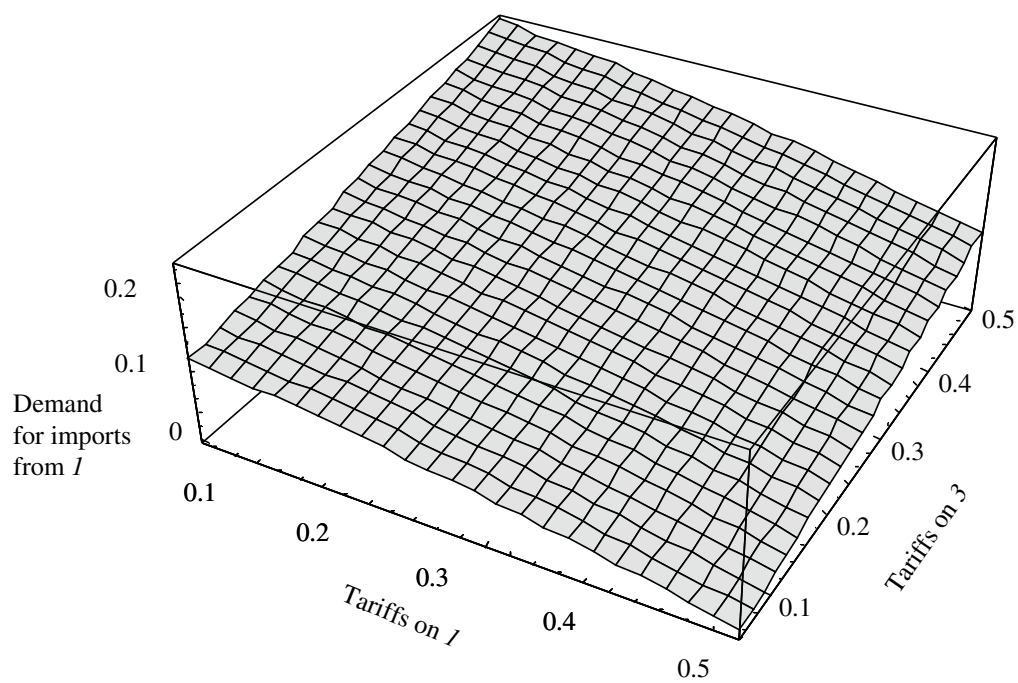

Notes: If country 2 imposes tariffs on countries 1 and 3 that are simply added to the production cost from each country $\left(g_{1}\right.$ and $\left.g_{3}\right)$, the demand for imports ( $\left.P^{*} q 1\right)$ from 1 as a function of tariffs on 1 and tariffs on 3 .

Source: Inter-American Development Bank based on official national sources.

Tariffs that country 2 imposes on each trading partner can be modeled as a simple increase in marginal production costs. Thus, the trade-reducing effect of a tariff that country 2 imposes on country 1 , for example, is a function of the tariff that country 2 imposes on country 3 . That is, the effect of the tariff on bilateral trade is a function of the "multilateral resistance" that is represented here as country 2 's tariff on all other countries (which, in this case, includes just country 3 ).

Figure 7 graphs the effects of country 2's imports from country 1 as a function of 2's tariffs on imports from countries 1 and 3 . When tariffs on imports from 3 are zero, higher tariffs on country 1 cause import (values) to fall, as the line in the facing plane (in the $\{$ trade,t 1$\}$ space) shows. The effect of the tariff on imports from 1, however, is affected by 2's tariff on country 3. Higher tariffs on imports from 3 reduce the trade-suppressing effect of tariffs on 1 , which is due to the trade diverting effect of 2's tariffs on 3. Higher tariffs on country 3 divert trade from 3 to 1 , making the tariff on 1 's exports less effective. Krishna's (1998) insight is that trade diversion that occurs from bilateral tariff changes (e.g. through a bilateral trade agreement) reduce the gains from extending the agreement to third parties. This result is evident in Figure 7, and it illustrates both that the estimated effect of bilateral tariffs can reflect trade diversion and the importance of focusing on multilateral resistance measures in empirical estimates of the effects of tariffs. 
The standard empirical tool used to analyze trade volumes is the gravity model. The gravity model has a rich history and has recently experienced an important resurgence (e.g. Evenett and Keller 2002, Hanson and Xiang 2004). AW show that multilateral resistance can be easily incorporated into the gravity model. Their theoretic focus is on trade costs, which, in their empirical work, justifies a focus on the effects of distance. Here we focus on tariff component of trade costs. Following AW, a theoretically correct representation of the gravity model begins with the assumption that all goods are differentiated by place of origin. This assumption suggests that each country produces only one good. Since we are interested in aggregate goods' flows, this assumption provides a reasonable starting point.

The second assumption is that consumers have identical, homothetic preferences that can be approximated with a CES utility function. AW, for example, specify the following function for consumers in country $j$ consuming goods $c$ from country $i$ :

$$
\left(\sum_{i} \beta_{i}^{(1-\sigma) / \sigma} c_{i j}^{(\sigma-1) / \sigma}\right)^{\sigma /(\sigma-1)}
$$

which is maximized according to the budget constraint

$$
\sum_{i} p_{i j} c_{i j}=y_{j}
$$

Define $\sigma$ as the constant elasticity of substitution between goods from each country, $\beta_{i}$ as a positive consumption weight (summing over $i$ to one), $p_{i j}$ as the price of region $i$ goods in country $j$, and finally $y_{j}$ as the nominal income of consumers in country $j$. Maximizing (2) subject to (3) generates the following demand $^{5}$ for country $i$ goods in country $j$ :

$$
z_{i j}=\frac{y_{j}\left(\beta_{i} p_{i j}\right)^{1-\sigma}}{\sum_{i}\left(\beta_{i} p_{i j}\right)^{1-\sigma}}
$$

in which $z_{i j}=p_{i j} c_{i j}$ represents country $j$ 's imports from country $i$.

Since our focus is on tariffs, we next assume that tariffs are the only factors that affect the price (we incorporate distance shortly) and allow incomplete "pass through" from tariffs to prices captured by the coefficient $\eta$.

$$
p_{i j}=p_{i} t_{i j}^{\eta}
$$

\footnotetext{
5 The complete derivation is included in the Appendix.
} 
We then follow Anderson (1979) and Deardorff (1998) who complete the derivation by noting that market clearance implies that each country's income is equal to the sum of the production shipped to each country,

$$
y_{i}=\sum_{j} z_{i j}
$$
leads to

Defining world income as $y^{w}=\sum_{j} y_{j}$ and income shares as $\theta_{j}=y_{j} / y^{w}$

$$
z_{i j}=\frac{y_{i} y_{j}}{y^{w}}\left(\frac{t_{i j}^{\eta}}{Q_{i} P_{j}}\right)^{1-\sigma}
$$

in which

$$
\begin{aligned}
& Q_{i}=\left(\sum_{j}\left(t_{i j}^{\eta} / P_{j}\right)^{1-\sigma} \theta_{j}\right)^{1 /(1-\sigma)} \\
& P_{j}=\left(\sum_{i}\left(\beta_{i} p_{i}\right)^{1-\sigma}\right)^{1 /(1-\sigma)}
\end{aligned}
$$

Our focus is not only on tariff levels, but the evolution of tariffs over time. Thus, we assume that distance is a fixed cost that acts as a demand "shifter" rather than a variable that causes a movement along the demand curve. Although differing somewhat from the current literature, we think this is a reasonable interpretation of the effects of distance in our context for several reasons. First, distance is symmetric and constant over time ${ }^{6}$. Second, countries that are far apart will consistently buy less from each other regardless of temporal deviations in price. That is, distance is less likely to cause a movement along the demand curve than a shift in the curve. Third, treating distance as a demand shifter allows us to focus on the effects of tariffs and to estimate the elasticity of substitution directly (as AW cannot do, but note is possible with asymmetric tariff data). We therefore define imports as exports minus a transportation $\operatorname{cost}^{7}$ (the traditional iceberg assumption):

6 Shipping costs may be neither constant nor symmetric (see Hummels 2001b). In fact, it is likely that they have declined over the long run. We therefore allow the effect of distance to change over time in our empirical work.

${ }^{7}$ We worried about the fact that we exclude the effects of average distance in this specification because this was one of the key contributions of AW. As we show in the robustness section, however, similar results emerge when the average distance variables are included in OLS regressions. We believe that this may be due to the fact that we focus on the Americas, which are geographically concentrated countries, and that we focus on the effects over time. Our solver refused to produce estimates when average distance was included multiplicatively with tariffs, which did not bother us too much because, as Hummels (2001b) points out, the interpretation of results generated by multiplying distance and tariffs seems problematic. 
FIGURE 8

\section{CROSS-TARIFF REDUCTION EFFECTS}

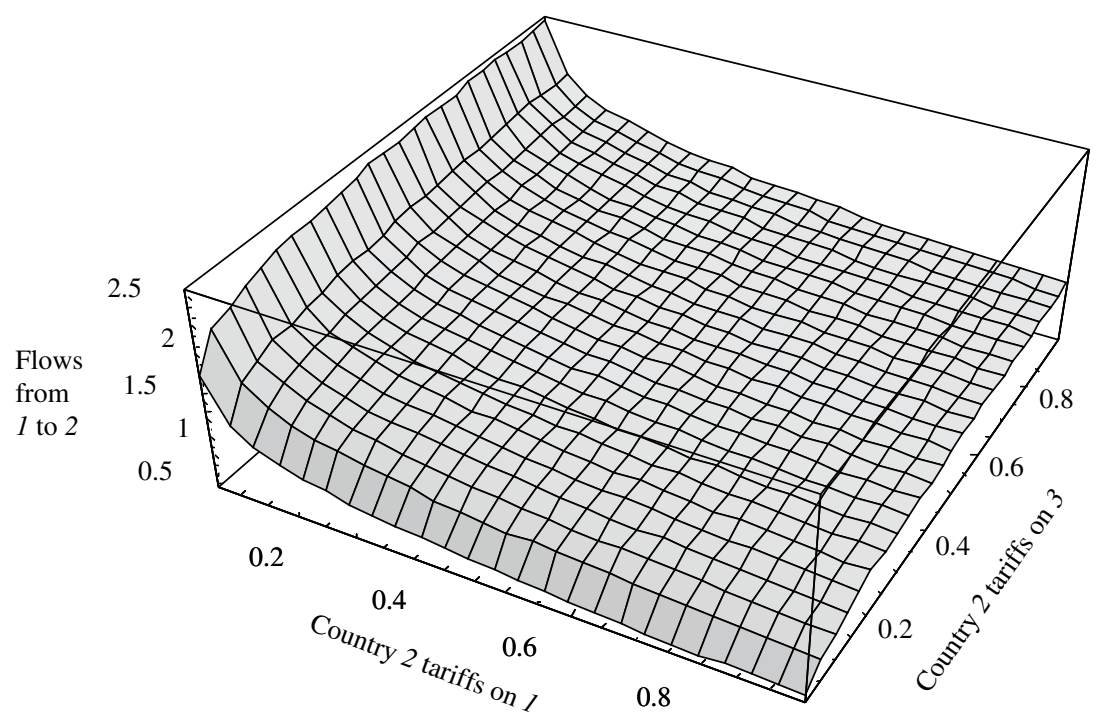

Notes: Results from a four-country simulation of the derived demand system in (7) and (8) in which $\eta, y_{i}, y_{j}$, and $y^{w}$ are set to one. A simple 3-country Cournot model, such as that postulated by Krisha (1998), exhibits similar properties. See Figure 1.

Source: Inter-American Development Bank based on official national sources.

$$
\ln z_{i j}=\ln x_{i j}-\ln \left(d_{i j}^{\alpha}\right)
$$

Combining (7) and (9) and taking natural logs of both sides gives us our gravity model:

$$
\begin{aligned}
\ln x_{i j} & =\ln y_{i}+\ln y_{j}-\ln y^{w}+\alpha \ln d_{i j}+ \\
& +(1-\sigma) \eta \ln t_{i j}-(1-\sigma) \ln Q_{i}-(1-\sigma) \ln P_{j}
\end{aligned}
$$

This specification suggests that both the level and overall average of tariffs affect trade volumes. This multilateral resistance approach suggests that not only do bilateral tariffs matter, but they matter when compared to average tariff levels. This result suggests an alternative metric for trade diversion. When two countries enter into a trade agreement and trade between them rises while trade between other partners falls, the tariffs that agreement countries have on third parties become more effective.

To illustrate this point, we calibrate the demand system (7)-(9) above for four countries $(1,2,3,4)$ and examine how a reduction in 2 's tariff on 3 affects the trade between 2 and 1 for a range of 2 's tariffs on country 1 's goods. The results are shown in Figure 8. Not surprisingly, Figure 8 is very similar to Figure 7. As 2's 
tariffs on 1 fall, trade between 1 and 2 increases, as expected. The trade-reducing effect of any given tariff 2 imposes on 1 , however, depends on the tariff 2 imposes on 3 . As 2 reduces tariffs on 3, trade between 1 and 2 falls and 2's tariffs on 1 become more effective in the sense that, at any given tariff level, trade is lower.

The intuition is very straightforward. In both the AW and Krishna models, lower tariffs on 3 cause 3 's exports to 2 to rise and l's exports to 2 to fall: trade is diverted from 1 to 3 . The real effects of tariffs are therefore dependent on average tariffs, or the "multilateral resistance" generated by other tariffs. The changing effect of asymmetric specific tariffs therefore offers a metric of trade diversion.

This metric of trade diversion differs from other recent innovations in the literature. Romalis (2002) examines trade diversion by looking at how trade between Mexico, the United States, and Canada changed following the North American Free Trade Agreement (NAFTA) by comparing trade between these countries and trade with Europe. This is a novel approach and works well when one wants to focus on a trade agreement. In the Americas, most bilateral agreements have prolonged "phase-in" periods that suggest that focusing on asymmetric tariffs is important.

\section{Estimation Strategy}

Our basic strategy begins by specifying a stochastic form of (10):

$$
\begin{aligned}
\ln x_{i j} & =k+\ln y_{i}+\ln y_{j}+\alpha \ln d_{i j}+(1-\sigma) \eta \ln t_{i j}- \\
& -(1-\sigma) \ln Q_{i}-(1-\sigma) \ln P_{j}+e_{i j}
\end{aligned}
$$

AW suggest that the most theoretically consistent approach to estimating these parameters would be to find the $\eta, \sigma, \alpha$, and a constant term $k$, that solve the following nonlinear optimization problem ${ }^{8}$ :

$$
\begin{gathered}
\min _{k, \alpha, \sigma, \eta} \sum_{i} \sum_{j \neq i}\left(\ln x_{i j}-k-\ln y_{i}-\ln y_{j}-\alpha \ln d_{i j}-(1-\sigma) \eta \ln t_{i j}+\right. \\
\left.+(1-\sigma) \ln Q_{i}+(1-\sigma) \ln P_{j}\right)^{2}
\end{gathered}
$$

subject to

$$
\begin{aligned}
& Q_{i}=\left(\sum_{j}\left(t_{i j}^{\eta} / P_{j}\right)^{1-\sigma} \theta_{j}\right)^{1 /(1-\sigma)} \\
& P_{j}=\left(\sum_{i}\left(t_{i j}^{\eta} / N\right)^{1-\sigma}\right)^{1 /(1-\sigma)}
\end{aligned}
$$

\footnotetext{
8 The second condition differs from (8) because we substitute (5) and assume that goods are evenly weighted across countries (the betas are identical for all countries and sum to one).
} 
Baier and Bergstrand (2005) argue that the nonlinear optimization approach is unnecessary when using the gravity model to resolve the "border puzzle" and other issues. Their derivation, however, like AW, assumes symmetric trade costs. When tariffs are asymmetric, as in our case, it is not clear that their OLS approach is similar to the nonlinear optimization approach. In the results section, we begin with results generated from solving this problem and then compare the solver results with those generated by unconstrained and constrained OLS and show how the estimates of the tariff effect change when average tariffs (and other variables) are added.

\section{EMPIRICAL RESULTS}

Table 2 contains the results from the minimization problem described in (12) and (13). Our data range from 1985-1997, and we calculated parameter estimates for each year by solving (12) and (13) separately for each year. Like AW, we do

TABLE 2

SOLVER ESTIMATES

\begin{tabular}{|c|c|c|c|c|}
\hline Year & $\begin{array}{c}\mathrm{k} \\
\text { constant }\end{array}$ & $\begin{array}{c}\alpha \\
\text { distance }\end{array}$ & $\begin{array}{c}\sigma \\
\text { elast. sub. }\end{array}$ & $\eta_{\text {tariffs }}^{\eta}$ \\
\hline 1985 & -13.715 & -1.041 & 1.391 & 1.198 \\
\hline 1986 & -0.516 & -1.852 & 14.201 & -1.225 \\
\hline 1987 & -0.647 & -1.878 & 10.972 & -1.237 \\
\hline 1988 & -0.962 & -1.889 & 8.744 & -1.244 \\
\hline 1989 & -0.589 & -2.092 & 4.783 & -1.216 \\
\hline 1990 & -0.731 & -2.263 & 3.505 & -1.217 \\
\hline 1991 & -3.051 & -1.700 & 8.108 & -1.344 \\
\hline 1992 & -3.980 & -1.686 & 6.551 & -1.375 \\
\hline 1993 & -7.325 & -1.377 & 5.896 & -1.508 \\
\hline 1994 & -6.406 & -1.464 & 6.927 & -1.454 \\
\hline 1995 & -5.513 & -1.518 & 7.392 & -1.428 \\
\hline 1996 & -6.455 & -1.394 & 7.663 & -1.485 \\
\hline 1997 & -119.663 & -0.148 & 11.116 & -1.938 \\
\hline $85-87$ & -1.068 & -1.454 & 2.542 & -1.630 \\
\hline $88-90$ & -0.754 & -2.137 & 4.078 & -1.230 \\
\hline $91-93$ & -4.042 & -1.660 & 7.530 & -1.371 \\
\hline $94-96$ & -6.230 & -1.421 & 7.170 & -1.473 \\
\hline 97 & -119.663 & -0.148 & 11.116 & -1.938 \\
\hline
\end{tabular}

Notes: Tariff coefficients and their standard errors were also calculated using bootstrapping. The coefficients were found to increase over time, ranging from -3.973 to -51.122 . The standard errors also increased over time, ranging from 0.039 to 2.008 .

Source: Own estimations. 
not report standard errors for our estimates ${ }^{9}$. Several interesting results emerge from Table 2. The elasticity of substitution estimates are greater than one in all years. The distance estimates are negative (as expected), rise (in absolute value) between 1985 and 1990, and fall (in absolute value) between 1990 and 1997.

With the exception of 1985, all of the estimates of the effects of tariffs are negative. The tariff estimates are generally in the range of, albeit on the high side, estimates found elsewhere in the literature. Unlike the distance estimates, they increase (in absolute value) after 1990. The growing effect of tariffs over time is consistent with the idea of growing trade diversion. The absolute values of the tariff effect are larger after 1990, the year that many of these bilateral agreements began to go into effect, than in the years 1986-1990. To the extent that Krishna's model applies to the Americas, these results are consistent with rising trade diversion contributing to the falling enthusiasm for the FTAA.

In addition to the annual estimates, the table also contains results from solving the model with pooled data. We solved the model pooling data over 198587, 1988-90, 1991-1993, 1994-1996, and 1997 to get an idea of the sensitivity to changes in sample period. Like the earlier results, the estimated tariff effect rises consistently between 1988 and 1997, which, again, is consistent with rising trade diversion.

\section{RoBUSTNESS}

Our estimation approach follows AW, but diverges somewhat from the gravity model literature that generally relies on cross section and/or OLS estimation. To explore the robustness of our estimation approach and results, we also present cross-section and panel OLS estimates. The gravity model that is more likely to be found in the literature might look something like:

$$
\ln x_{i j}=k+\beta_{1} \ln y_{i}+\beta_{2} \ln y_{j}+\beta_{3} \ln d_{i j}+\beta_{4} \ln t_{i j}+\beta_{5} \Phi_{i t}+e_{i j}
$$

in which $\beta_{5}$ is actually a vector of parameters that reflect the effects of the variables contained in $\Phi$. These variables may include controls for common borders, languages, or other characteristics, but has not traditionally contained controls for average tariff levels.

One important difference between this specification and equation (11) is the interpretation of the coefficient on the tariff variable. In most of the gravity model literature that includes tariff estimates, the coefficient on tariffs in equation (14) is interpreted as the direct effect of tariffs (that is, as $\eta$ ). Without the appropriate multilateral resistance terms and corresponding theoretical foundation, most gravity specifications abstract from the elasticity of substitution component. In the solver approach, however, it is possible to separate the two terms. In the

\footnotetext{
9 One reason the gravity model is so heavily used is that statistical significance of the main variables is rarely an issue. Our OLS estimates, described in the next section, show no cause for concern about statistical significance.
} 
results that follow, we follow the convention in the gravity literature (for the sake of comparability) and interpret $\beta_{5}$ as $\eta$.

Table 3 contains the results from 5 different gravity specifications. All five columns contain OLS estimates using the log of exports as the dependent variable. For these results, we pooled data from 1985 to $1997^{10}$. We begin with the most basic, column (1), specification that includes (natural logs of) the tariff rate $(1+$ tariff), distance, the GDP of each partner (importer and exporter), and a constant term. In the second column we add dummy variables that traditionally appear in gravity models that account for a common border, either being landlocked, either being an island, and having a common language. In the third column we exclude these dummy variables but include the average tariff rate of each country. In the fourth column, we include both the average tariff rates of each country and the traditional dummie variables. The final column excludes these traditional variables but adds the average distance to the rest of the world for each country.

The results in the first column seem to suggest the importance of the excluded multilateral resistance measures. The estimates of distance and the GDP of each country are consistent with prior expectations, but the tariff effect is positive. When the traditional gravity model variables are included in column (2), the tariff effect becomes negative, as expected, perhaps suggesting that these variables are correlated with the country-specific effects of average tariffs and therefore may pick up some of their effect. Note that their inclusion has little effect on the other variables and, with the exception of being an island, they all are statistically significant.

When we replace the traditional variables with the average tariff rate, we find an estimate of the tariff effect that is much larger (in absolute value) than our solver estimate, while, again, our other estimates change little. Including the traditional gravity variables with our average tariff rate generates a still larger estimate of the tariff effect but has only a small effect on the average tariff effect estimates, as seen in column (4). Finally, column (5) shows that a similar tariff effect estimate emerges when we include the average distance measures along with the average tariff measures. The main point from this table is that multilateral resistance measures matter in the sense that including them affects the tariff effect estimates.

In addition to multilateral resistance, theory also implies several constraints. Moving closer to theory, Table 4 contains the constrained OLS estimates in four columns. In the first column, we constrain the coefficient on the income terms to equal one. In the second column, we constrain the coefficients on the average tariff variables to be equal to each other. In the third column, we constrain the income coefficients to equal one and include country specific (not pair specific) fixed effects ${ }^{11}$. In the last column, we constrain the income variables to one and the average tariff variable coefficients to equal each other.

\footnotetext{
10 This period is chosen to be comparable with the pooled solver results. We also discuss year-byyear results shortly.

11 We do not include pair-specific fixed effects for several reasons. First, the theory suggests that the multilateral resistance measures are country-specific, implying country-specific fixed effects. Second, perhaps not surprisingly, we do not get significant estimates when including pair-specific fixed effects, since the pair-specific fixed effects results are identified from purely time-series variation, which is not strictly consistent with theory.
} 
TABLE 3

CROSS SECTION ESTIMATES

Dependent variable: logarithm of exports

\begin{tabular}{|c|c|c|c|c|c|}
\hline & $\begin{array}{l}\text { (1) } \\
\text { Base }\end{array}$ & $\begin{array}{c}(2) \\
\text { Common }\end{array}$ & $\begin{array}{c}\text { (3) } \\
\text { Multilat. }\end{array}$ & $\begin{array}{c}\text { (4) } \\
\text { Mult } \\
\text { and } \\
\text { Common }\end{array}$ & $\begin{array}{c}(5) \\
\text { Multilat. } \\
\text { Dist. }\end{array}$ \\
\hline $\log (1+($ Tariff/100) $)$ & $\begin{array}{l}0.654 \\
(0.129)^{* * *}\end{array}$ & $\begin{array}{l}-0.313 \\
(0.132) * *\end{array}$ & $\begin{array}{l}-4.946 \\
(0.792) * * *\end{array}$ & $\begin{array}{l}-9.490 \\
(0.790) * * *\end{array}$ & $\begin{array}{l}-5.673 \\
(0.859)^{* * * *}\end{array}$ \\
\hline Ln Distance & $\begin{array}{l}-1.195 \\
(0.013)^{* * *}\end{array}$ & $\begin{array}{l}-1.053 \\
(0.015)^{* * *}\end{array}$ & $\begin{array}{l}-1.080 \\
(0.021)^{* * *}\end{array}$ & $\begin{array}{l}-0.844 \\
(0.023) * * *\end{array}$ & $\begin{array}{l}-1.113 \\
(0.024)^{* * * *}\end{array}$ \\
\hline Ln Real Gdp Exporter & $\begin{array}{l}0.969 \\
(0.007)^{* * *}\end{array}$ & $\begin{array}{l}0.939 \\
(0.007)^{* * * *}\end{array}$ & $\begin{array}{l}0.846 \\
(0.007)^{* * *}\end{array}$ & $\begin{array}{l}0.799 \\
(0.007)^{* * *}\end{array}$ & $\begin{array}{l}0.848 \\
(0.007)^{* * * *}\end{array}$ \\
\hline Ln Real Gdp Importer & $\begin{array}{l}0.846 \\
(0.007)^{* * *}\end{array}$ & $\begin{array}{l}0.796 \\
(0.008)^{* * *}\end{array}$ & $\begin{array}{l}0.975 \\
(0.007)^{* * *}\end{array}$ & $\begin{array}{l}0.948 \\
(0.007)^{* * *}\end{array}$ & $\begin{array}{l}0.986 \\
(0.007)^{* * *}\end{array}$ \\
\hline Common Border & & $\begin{array}{l}0.725 \\
(0.048) * * *\end{array}$ & & $\begin{array}{l}0.822 \\
(0.048) * * *\end{array}$ & \\
\hline Either Is Landlocked & & $\begin{array}{l}-0.656 \\
(0.032)^{* * *}\end{array}$ & & $\begin{array}{l}-0.670 \\
(0.032)^{* * *}\end{array}$ & \\
\hline Either Is An Island & & $\begin{array}{c}0.039 \\
(0.030)\end{array}$ & & $\begin{array}{c}-0.003 \\
(0.029)\end{array}$ & \\
\hline Common Language & & $\begin{array}{l}0.175 \\
(0.030)^{* * *}\end{array}$ & & $\begin{array}{l}0.200 \\
(0.030)^{* * *}\end{array}$ & \\
\hline Log Avg Exp Tariff & & & $\begin{array}{l}3.122 \\
(0.353)^{* * *}\end{array}$ & $\begin{array}{l}3.436 \\
(0.341)^{* * * *}\end{array}$ & $\begin{array}{l}2.472 \\
(0.359) * * *\end{array}$ \\
\hline Log Avg Imp Tariff & & & $\begin{array}{l}5.168 \\
(0.770)^{* * *}\end{array}$ & $\begin{array}{l}8.591 \\
(0.759)^{* * *}\end{array}$ & $\begin{array}{l}5.956 \\
(0.858) * * *\end{array}$ \\
\hline Ln Avg Dist Reporter World & & & & & $\begin{array}{l}0.680 \\
(0.067) * * *\end{array}$ \\
\hline Ln Avg Dist Partner World & & & & & $\begin{array}{c}0.130 \\
(0.075)^{*}\end{array}$ \\
\hline Constant & $\begin{array}{l}-7.333 \\
(0.157)^{* * *}\end{array}$ & $\begin{array}{l}-7.388 \\
(0.181)^{* * *}\end{array}$ & $\begin{array}{l}-8.576 \\
(0.215)^{* * *}\end{array}$ & $\begin{array}{l}-9.468 \\
(0.241)^{* * * *}\end{array}$ & $\begin{array}{l}-15.141 \\
(0.812) * * *\end{array}$ \\
\hline Observations & 9,709 & 9,709 & 9,709 & 9,709 & 9,709 \\
\hline R-squared & 0.83 & 0.84 & 0.83 & 0.84 & 0.83 \\
\hline
\end{tabular}

Notes: Standard errors in parentheses. *,**,*** significant at $10 \%, 5 \%$ and $1 \%$ respectively. Source: Own estimations.

The results in the first column suggest that just constraining the income terms to equal one generates larger tariff effects to those generated with the solver. The average tariff coefficients suggest elasticities of substitution that are close to those generated from the solver ${ }^{12}$. Constraining the average tariff coefficients to be equal generates a somewhat smaller tariff effect. The distance coefficient is not affected by the change in constraints.

12 Based on the $Q$ and $P$ coefficients in equation (10), if $\mathrm{b}$ is the coefficient estimate and $\mathrm{s}$ is the elasticity of substitution, then $b=-(1-s)$, implying a range of estimates of the elasticity of substitution of 3.935 to 7.144 . 
TABLE 4

CONSTRAINED CROSS SECTION ESTIMATES

\begin{tabular}{lcccc}
\hline & $(1)$ & $(2)$ & $(3)$ & $(4)$ \\
& Income & Multilat & Fixed FX & All Cons \\
\hline Log(1+(Tariff/100)) & -4.894 & -3.191 & -0.193 & -2.129 \\
& $(0.810)^{* * *}$ & $(0.404)^{* * *}$ & $(0.145)$ & $(0.410)^{* * *}$ \\
Ln Distance & -1.081 & -1.117 & -1.215 & -1.140 \\
& $(0.021)^{* * *}$ & $(0.015)^{* * *}$ & $(0.012)^{* * *}$ & $(0.015)^{* * *}$ \\
Ln Real Gdp Exporter & 1.000 & 0.974 & 1.000 & 1.000 \\
& & $(0.007)^{* * *}$ & & \\
Ln Real Gdp Importer & 1.000 & 0.845 & 1.000 & 1.000 \\
& & $(0.007)^{* * *}$ & & 3.349 \\
Log Avg Tariff Exporter & 2.935 & 3.387 & & $(0.345)^{* * *}$ \\
& $(0.360)^{* * *}$ & $(0.338)^{* * *}$ & & 3.349 \\
Log Avg Tariff Importer & 6.144 & 3.387 & & $(0.345)^{* * *}$ \\
& $(0.786)^{* * *}$ & $(0.338)^{* * *}$ & & -9.268 \\
Constant & -10.812 & -8.283 & -10.377 \\
& $(0.176)^{* * *}$ & $(0.183)^{* * *}$ & $(0.123)^{* * *}$ & $(0.137)^{* * *}$ \\
\hline Observations & 9,709 & 9,709 & 9,709 & 9,709 \\
\hline
\end{tabular}

Notes: Standard errors in parentheses. *,**, *** significant at $10 \%, 5 \%$ and $1 \%$ respectively. The first column's regression included the constraint that the income coefficients equal one. The second column's regression constrained the average tariff coefficients to be equal. The regression in the third column includes country-specific fixed effects and constrains the income coefficients to equal one. The last column's regression constrains the income coefficients to equal one and the average tariff coefficients to equal each other.

Source: Own estimations.

When fixed effects are included, however, the tariff estimate falls dramatically to about $6 \%$ of the estimate in column (2). To the extent that including the multilateral tariff resistance measures generates similar estimates to those generated by the solver and these are closer to the "correct" estimates, the results in column (3) suggest that country-specific fixed effects are a poor substitute for multilateral resistance variables when tariffs are asymmetric.

In the final column, we apply all three constraints (each income coefficient is equal to one and the coefficients on the average tariff variables equal to each other). The resulting estimate of the tariff effect is the estimate in Table 4 that is most similar to the solver estimates. Changing the constraints and/or including fixed effects seems to have little effect on the estimate of the distance variable.

One key difference between the estimates presented in Tables 3 and 4 and the solver estimates is that the OLS estimates are not presented year-by-year. To investigate changes over time, we pool the data over time and include interaction terms for each year between 1985 and 1997 (leaving out 1988 as the reference year). These years mirror Figure 3 by capturing the different periods of trade liberalization in the Americas. The estimated coefficients on the tariff-year interactions suggest a growing negative effect of tariffs over time. The coefficient on the 1997 interaction term shows that the tariff effect in 1997 is statistically significantly larger (in absolute 
value) than the tariff effect in 1988. In both columns 1 and 2 the tariff effects are statistically different at the $1 \%$ level, while in the third regression the tariff effects are statistically different at the $10 \%$ level. Additionally, since the coefficient on the 1997 interaction term in the third regression has the correct sign as predicted by theory, it is appropriate to conduct a one-sided t-test. Based on the one-sided test, the tariff effects are statistically different at the 5\% level. In other words, there was a statistically and economically significant increase in trade diversion between 1988 and the end of the 1990s as subregional agreements proliferated.

Figure 9 presents the estimates of the tariff effects from year-by-year OLS regressions. We graph coefficients from annual estimates of equation 1 from Table 3 and equations 3 and 4 from Table 4 along with the solver estimates of the tariff effect. The "base" regression (the first equation in Table 3 ) generates increasingly positive tariff effects. Adding the multilateral variables, such as from equation 4 in Table 4, generates negative tariff effects that are at least 2-3 times larger in absolute value than the solver estimates. Including fixed effects generates negative tariff effects that are larger than the multilateral estimates, but exhibit a similar variance

FIGURE 9

COMPARISON OF TARIFF EFFECTS

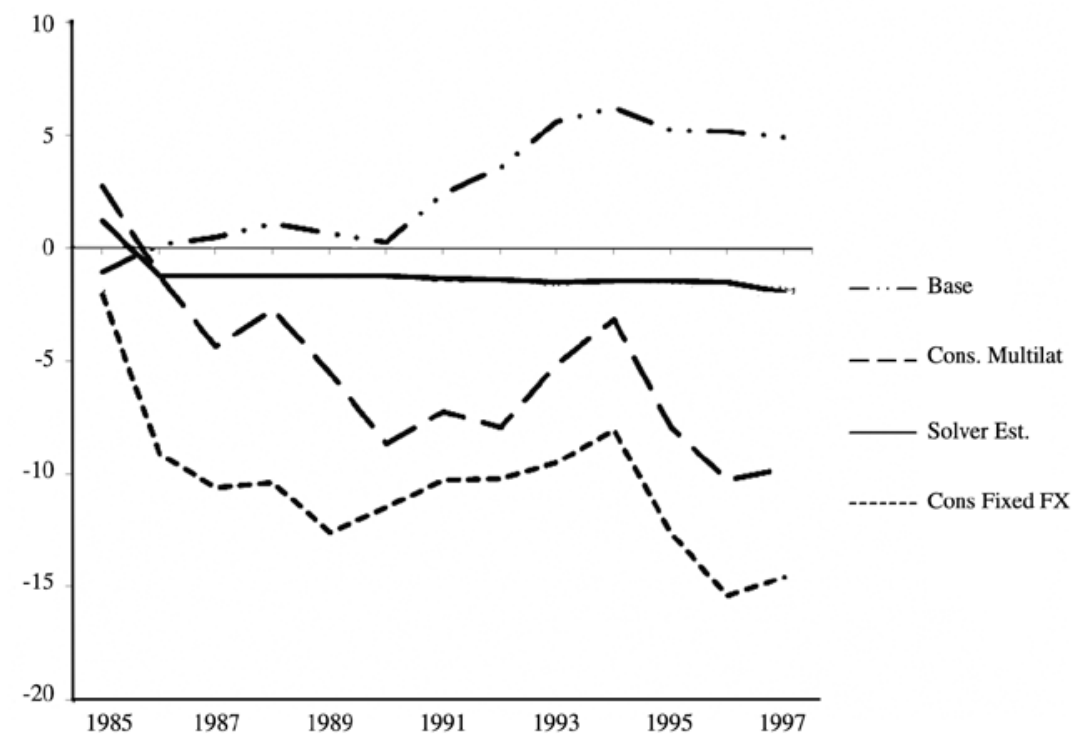

Notes: Each line represents coefficient estimates on the log tariff variable in year-by-year regressions. The "Base" regression also includes distance and income of each country. The "Cons Fixed FX" also contains country fixed effects and constrains the income coefficients to equal one. The "Cons Multilat" replaces the country fixed effects with average tariff rates for each country and constrains their coefficients to be equal (income coefficients were also constrained to be one). The "Solver Est" line graphs the results from solving the Anderson-van Wincoop type problem as described in the text.

Source: Own estimations. 
TABLE 5

FIXED EFFECTS WITH INTERACTION CROSS SECTION ESTIMATES

\begin{tabular}{|c|c|c|c|}
\hline & $\begin{array}{c}(1) \\
\text { No Cons }\end{array}$ & $\begin{array}{c}(2) \\
\text { Income }\end{array}$ & $\begin{array}{c}\text { (3) } \\
\text { Full Cons }\end{array}$ \\
\hline $\log (1+($ Tariff/100) $)$ & $\begin{array}{l}-1.553 \\
(0.302)^{* * *}\end{array}$ & $\begin{array}{l}-1.371 \\
(0.300) * * *\end{array}$ & $\begin{array}{l}-10.147 \\
(0.897) * * *\end{array}$ \\
\hline (85 Dummy)*Log(1+(Tariff/100)) & $\begin{array}{l}-1.162 \\
(0.359) * * *\end{array}$ & $\begin{array}{l}-1.668 \\
(0.342) * * *\end{array}$ & $\begin{array}{l}-1.766 \\
(0.340)^{* * *}\end{array}$ \\
\hline$(86$ Dummy)*Log $(1+($ Tariff/100)) & $\begin{array}{c}-0.096 \\
(0.341)\end{array}$ & $\begin{array}{c}-0.336 \\
(0.340)\end{array}$ & $\begin{array}{c}-0.440 \\
(0.338)\end{array}$ \\
\hline (87 Dummy)*Log(1+(Tariff/100)) & $\begin{array}{c}0.134 \\
(0.338)\end{array}$ & $\begin{array}{c}-0.009 \\
(0.339)\end{array}$ & $\begin{array}{c}-0.090 \\
(0.337)\end{array}$ \\
\hline (89 Dummy)*Log(1+(Tariff/100)) & $\begin{array}{l}-0.841 \\
(0.369) * *\end{array}$ & $\begin{array}{l}-0.870 \\
(0.373) * *\end{array}$ & $\begin{array}{l}-0.820 \\
(0.371)^{* *}\end{array}$ \\
\hline$(90$ Dummy)*Log(1+(Tariff/100)) & $\begin{array}{l}-2.294 \\
(0.491)^{* * *}\end{array}$ & $\begin{array}{l}-2.111 \\
(0.494) * * *\end{array}$ & $\begin{array}{l}-1.443 \\
(0.496)^{* * *}\end{array}$ \\
\hline (91 Dummy)*Log(1+(Tariff/100)) & $\begin{array}{l}-2.744 \\
(0.728) * * *\end{array}$ & $\begin{array}{l}-2.361 \\
(0.733)^{* * *}\end{array}$ & $\begin{array}{c}-0.749 \\
(0.745)\end{array}$ \\
\hline (92 Dummy)*Log(1+(Tariff/100)) & $\begin{array}{l}-3.187 \\
(0.851)^{* * *}\end{array}$ & $\begin{array}{l}-2.982 \\
(0.859) * *\end{array}$ & $\begin{array}{c}-0.950 \\
(0.877)\end{array}$ \\
\hline (93 Dummy)*Log(1+(Tariff/100)) & $\begin{array}{l}-2.819 \\
(0.928) * * *\end{array}$ & $\begin{array}{l}-3.403 \\
(0.933) * * *\end{array}$ & $\begin{array}{c}-1.149 \\
(0.953)\end{array}$ \\
\hline (94 Dummy)*Log(1+(Tariff/100)) & $\begin{array}{l}-2.611 \\
(0.936) * * *\end{array}$ & $\begin{array}{l}-3.503 \\
(0.935) * * *\end{array}$ & $\begin{array}{c}-1.210 \\
(0.956)\end{array}$ \\
\hline (95 Dummy)*Log(1+(Tariff/100)) & $\begin{array}{l}-2.847 \\
(0.920) * * *\end{array}$ & $\begin{array}{l}-3.308 \\
(0.924)^{* * *}\end{array}$ & $\begin{array}{c}-0.886 \\
(0.948)\end{array}$ \\
\hline (96 Dummy)*Log(1+(Tariff/100)) & $\begin{array}{l}-3.298 \\
(0.950) * * *\end{array}$ & $\begin{array}{l}-3.851 \\
(0.953)^{* * *}\end{array}$ & $\begin{array}{c}-1.439 \\
(0.976)\end{array}$ \\
\hline (97 Dummy)*Log(1+(Tariff/100)) & $\begin{array}{l}-2.917 \\
(0.965) * * *\end{array}$ & $\begin{array}{l}-4.056 \\
(0.954)^{* * * *}\end{array}$ & $\begin{array}{l}-1.643 \\
(0.977)^{*}\end{array}$ \\
\hline Ln Distance & $\begin{array}{l}-1.140 \\
(0.014) * * *\end{array}$ & $\begin{array}{l}-1.137 \\
(0.014)^{* * *}\end{array}$ & $\begin{array}{l}-0.969 \\
(0.022) * * *\end{array}$ \\
\hline Ln Real Gdp Exporter & $\begin{array}{l}0.152 \\
(0.063)^{* *}\end{array}$ & 1.000 & 1.000 \\
\hline Ln Real Gdp Importer & $\begin{array}{l}0.729 \\
(0.071)^{* * *}\end{array}$ & 1.000 & 1.000 \\
\hline Log Avg Tariff Exporter & & & $\begin{array}{l}9.578 \\
(0.923) * * *\end{array}$ \\
\hline Log Avg Tariff Importer & & & $\begin{array}{l}9.578 \\
(0.923)^{* * * *}\end{array}$ \\
\hline Constant & $\begin{array}{l}4.088 \\
(1.191)^{* * * *}\end{array}$ & $\begin{array}{l}-9.442 \\
(0.132)^{* * * *}\end{array}$ & $\begin{array}{l}-12.354 \\
(0.310) * * *\end{array}$ \\
\hline Observations & 9,709 & 9,709 & 9,709 \\
\hline
\end{tabular}

Notes: Standard errors in parentheses. ${ }^{*}, * *, * * *$ significant at $10 \%, 5 \%$ and $1 \%$ respectively. The first column's regression included country-specific fixed effects and no constraints. The second column's regression included country-specific fixed effects and constrains the income coefficients to equal one. The last column's regression included country-specific fixed effects and constrains the income coefficients to equal one and the average tariff coefficients to equal each other.

Source: Own estimations. 
(the annual changes are similar). The equations with the multilateral resistance effects show a growing (negative) effect of tariffs over time that matches the falling average tariffs and rising difference between the mean and average tariffs that is consistent with trade diversion. The solver estimates result in the most moderate increase in the effect of tariffs and the one with the smallest overall variance in annual changes. Overall, however, the results all suggest rising trade diversion throughout the 1990s.

\section{Conclusions}

Policymaker and academics alike have been engaged in a vigorous debate over the best way to achieve economic integration. The two main approaches are multilateral negotiations and expanding bilateral negotiations. The relative success of the GATT and the WTO over the last 50 years reveals the potential benefits from multilateral negotiations. While both may occur simultaneously, our results suggest that allowing or pursuing bilateral negotiations reduces the potential gains from multilateral negotiations because we find evidence of trade diversion, which is generally believed to be economically inefficient and reduces the gains from multilateral negotiations. Krishna (1998) and others have suggested that bilateral agreements can hinder multilateral agreements. Since the overall gains from multilateral agreements are potentially quite large (Brown et al. 2003), understanding how bilateral agreements affect multilateral negotiations is a critical question for policy.

Specifically, we do this by combining two important contributions. We show how Krishna's insights can be incorporated into the gravity model using the multilateral resistance approach implemented by Anderson and van Wincoop (2003). By adapting this approach to asymmetric tariffs, we illustrate how this concept can be used to help measure trade diversion in the multilateral context. Our results suggest that omitted average tariff levels create an important omitted variable bias in gravity models. Including these measures can help illustrate the potential effects of trade diversion that occur when countries pursue bilateral agreements.

We apply this approach to Latin America. Latin America is particularly appropriate to address this question because the recent proliferation of bilateral agreements has coincided with declining enthusiasm for further multilateral liberalization. Using several different estimation approaches, we find significant evidence of an increasing tariff effect that is consistent with trade diversion. These results are consistent with Krishna's suggestion that bilateral agreements that induce trade diversion can reduce the incentives to pursue multilateral trade agreements.

Our paper is consistent with other recent work on regionalism in Latin America that shows that the rise of bilateralism is not necessarily a negative development. Estevadeordal, Freund, and Ornelas (2008) suggest that as countries adopt bilateral agreements, they also tend to reduce product-specific MFN tariffs. 
They suggest that this behavior could be an attempt by governments to avoid or offset the trade-diverting effects of bilateral agreements, such as the kind we find in this paper. Furthermore, by understanding the potential and actual trade diverting effects of bilateral agreements, governments can address the potential problems in ways that effectively spread free trade throughout the region, such as described by Estevadeordal, Harris, and Suominen (2007) in the context of Rules of Origin.

It is important to highlight what we do not show with our results. We do not show that the increase in trade diversion explains the lack of enthusiasm for the FTAA. Linking the rise in trade diversion with the potential welfare effects of the FTAA would involve country-specific analysis beyond the scope of this paper, and therefore is left for future research. In the meantime, however, documenting changes in trade diversion is a potentially important first step towards effective trade policies in the region.

\section{REFERENCES}

Anderson, J. E. (1979), "A Theoretical Foundation for the Gravity Equation" American Economic Review 69 (1): 106-116.

Anderson, J. E and E. Van Wincoop (2003), "Gravity with Gravitas: A Solution to the Border Puzzle" American Economic Review, 93 (1): 170-92.

Baier, S. and J. Bergstrand (2005), "Bonus Vetus OLS: A Simple OLS Approach for Addressing the 'Border Puzzle' and Other Gravity-Equation Issues" mimeo.

Brown, D.K, A. V. Deardorff and R.M. Stern (2003), "Multilateral, Regional and Bilateral Trade-Policy Options for the United States and Japan" World Economy, 26 (6): 803-28.

Deardorff, A.V. (1998), "Determinants of Bilateral Trade: Does Gravity Work in a Neoclassical World?" in Frankel, J.A. (eds), "The Regionalization of the World Economy”, NBER Project Report series. Chicago and London: University of Chicago Press.

Estevedeordal, A., C. Freund and E. Ornelas (2008), "Does Regionalism Affect Trade Liberalization towards Non-Members?" mimeo.

Estevedeordal, A., J. Harris and K. Suominen (2007), "Multilateralising Preferential Rules of Origin around the World", mimeo, prepared for WTO/HEI/NCCR Trade/ CEPR Conference, Geneva, Switzerland.

Ethier, W. J. (1998a), “The New Regionalism” Economic Journal 108 (449): 1149-61.

Ethier, W. J. (1998b), "Regionalism in a Multilateral World", Journal of Political Economy, 106 (6): 1214-45.

Evenett, S. J. and W. Keller (2002), "On Theories Explaining the Success of the Gravity Equation" Journal of Political Economy, 110 (2)2:281-316.

Hanson, G. and Ch. Xiang, (2004), "The Home-Market Effect and Bilateral Trade Patterns" American Economic Review 94 (4): 1108-29.

Hummels, D. (2001a), “Towards a Geography of Trade Costs”, Purdue University, 2001a, mimeo.

Hummels, D. (2001b), “Have International Transportation Costs Declined?" Purdue University, mimeo.

Krishna, P. (1998), "Regionalism and Multilateralism: A Political Economy Approach" Quarterly Journal of Economics, 113 (1): 227-51. 
Krueger, A. O. (1995), American Trade Policy: A Tragedy in the Making. AEI Press.

Limao, N. and A. J. Venables (2001), "Infrastructure, Geographical Disadvantage, Transport Costs, and Trade". The World Bank Economic Review, 15 (3).

Romalis, J. (2001), "NAFTA's Impact on North American Trade", mimeo 2001, Chicago GSB.

Rose, A.K. (2004), "Do We Really Know That the WTO Increases Trade?" American Economic Review, 94 (1): 98-114. 


\section{APPENDIX \\ DERIVATION OF THE DEMAND FUNCTIONS}

Following the specification of Anderson and van Wincoop (2000), a theoretically correct representation of the gravity model begins with the assumption that all goods are differentiated by place of origin. This assumption suggests that each country produces only one good. At this stage, in which we are interested in the affect of average tariff levels on aggregate flows of goods, this assumption provides a reasonable starting point.

The second assumption is that consumers have identical, homothetic preferences that can be approximated with a CES utility function. Anderson and van Wincoop (2000), for example, specify the following function for consumers in country $j$ consuming goods $\mathrm{z}$ from country $i$ :

$$
\left(\sum_{i} \beta_{i}^{(1-\sigma) / \sigma} z_{i j}^{(\sigma-1) / \sigma}\right)^{\sigma /(\sigma-1)}
$$

which is maximized according to the budget constraint

$$
\sum_{i} p_{i j} z_{i j}=y_{j}
$$

Define $\sigma$ as the constant elasticity of substitution between goods from each country, $\beta_{i}$ as a positive consumption weight (summing over $i$ to one), $p_{i j}$ as the price of region $i$ goods in country $j$, and finally $y_{j}$ as the nominal income of consumers in country $j$.

$$
L=\left(\sum_{i}^{N} \beta_{i}^{\frac{1-\sigma}{\sigma}} z_{i j}^{\frac{\sigma-1}{\sigma}}\right)^{\frac{\sigma}{\sigma-1}}+\lambda\left[y_{j}-\sum_{i}^{N} p_{i j} z_{i j}\right]
$$

Next we drop the $j$ by just looking at the maximization problem for people in country $j$.

$$
L_{j}=\left(\sum_{i}^{N} \beta_{i}^{\frac{1-\sigma}{\sigma}} z_{i}^{\frac{\sigma-1}{\sigma}}\right)^{\frac{\sigma}{\sigma-1}}+\lambda\left[y-\sum_{i}^{N} p_{i} z_{i}\right]
$$

Maximize (A4) by taking the derivative with respect to each $z_{i}$. For each $i$ we get

$$
\partial L / \partial z_{i}=\frac{\sigma}{\sigma-1}\left(\sum_{i}^{N} \beta_{i}^{\frac{1-\sigma}{\sigma}} z_{i}^{\frac{\sigma-1}{\sigma}}\right)^{\frac{\sigma}{\sigma-1}-1} \frac{\sigma-1}{\sigma} \beta_{i}^{\frac{1-\sigma}{\sigma}} z_{i}^{\frac{\sigma-1}{\sigma}-1}-\lambda p_{i} z_{i}=0
$$


we now have:

Recall that $U_{j}=\left(\sum_{i} \beta_{i}^{(1-\sigma) / \sigma} z_{i}^{(\sigma-1) / \sigma}\right)^{\sigma /(\sigma-1)}$ and that $\frac{\sigma-1}{\sigma}-1=\frac{\sigma-1}{\sigma}-\frac{\sigma}{\sigma}=-\frac{1}{\sigma}$

$$
U \beta_{i}^{\frac{1-\sigma}{\sigma}} z_{i}^{-\frac{1}{\sigma}}=\lambda\left(\sum_{i}^{N} \beta_{i}^{\frac{1-\sigma}{\sigma}} z_{i}^{\frac{\sigma-1}{\sigma}}\right) p_{i}
$$

which can be written as

$$
U \beta_{i}^{\frac{1-\sigma}{\sigma}} z_{i}^{\frac{\sigma-1}{\sigma}}=\lambda\left(\sum_{i}^{N} \beta_{i}^{\frac{1-\sigma}{\sigma}} z_{i}^{\frac{\sigma-1}{\sigma}}\right) p_{i} z_{i}
$$

The next step is to sum over all $\mathrm{N}$ goods which will allow us to simplify the problem because the terms in red cancel out:

$$
U \sum_{i}^{N} \beta_{i}^{\frac{1-\sigma}{\sigma}} z_{i}^{\frac{\sigma-1}{\sigma}}=\lambda\left(\sum_{i}^{N} \beta_{i}^{\frac{1-\sigma}{\sigma}} z_{i}^{\frac{\sigma-1}{\sigma}}\right) \sum_{i}^{N} p_{i} z_{i}
$$

so that we are left with

$$
U=\lambda \sum_{i}^{N} p_{i} z_{i}
$$

If we are operating on our budget constraint, then $y_{j}=\sum_{i}^{N} p_{i} z_{i}$.

Therefore, $\left(\sum_{i} \beta_{i}^{(1-\sigma) / \sigma} z_{i}^{(\sigma-1) / \sigma}\right)=(\lambda y)^{\frac{\sigma-1}{\sigma}}$ (and that $\mathrm{U} / \lambda=y$ and $\left.\mathrm{U} / y=\lambda\right)$.

From (8) we can now see that

$$
\frac{U}{\lambda} \beta_{i}^{\frac{1-\sigma}{\sigma}} z_{i}^{\frac{\sigma-1}{\sigma}}=\left(\sum_{i}^{N} \beta_{i}^{\frac{1-\sigma}{\sigma}} z_{i}^{\frac{\sigma-1}{\sigma}}\right) p_{i} z_{i}
$$

which implies that

$$
y \beta_{i}^{\frac{1-\sigma}{\sigma}} z_{i}^{\frac{\sigma-1}{\sigma}}=(\lambda y)^{\frac{\sigma-1}{\sigma}} p_{i} z_{i}=\lambda^{\frac{\sigma-1}{\sigma}} y^{\frac{\sigma-1}{\sigma}} p_{i} z_{i}
$$

Collecting the $y$ terms to the left and the $\mathrm{z}$ terms to the right, we get

$$
y^{\frac{\sigma}{\sigma}-\left(\frac{\sigma-1}{\sigma}\right)} \beta_{i}^{\frac{1-\sigma}{\sigma}}=\lambda^{\frac{\sigma-1}{\sigma}} p_{i} z_{i}^{\frac{\sigma}{\sigma}-\left(\frac{\sigma-1}{\sigma}\right)}
$$

which is

$$
y^{\frac{1}{\sigma}} \beta_{i}^{\frac{1-\sigma}{\sigma}}=\lambda^{\frac{\sigma-1}{\sigma}} p_{i} z_{i}^{\frac{1}{\sigma}}
$$


Raising both sides to the power of $\sigma$ generates the following result.

(A14)

$$
y \beta_{i}^{1-\sigma}=\lambda^{\sigma-1} p_{i}^{\sigma} z_{i}
$$

Multiply both sides by $p_{i}^{1-\sigma}$ and sum again over all $\mathrm{N}$ goods to get

$$
y \sum_{i}^{N} \beta_{i}^{1-\sigma} p_{i}^{1-\sigma}=\lambda^{\sigma-1} \sum_{i}^{N} p_{i} z_{i}
$$

Once again, the terms cancel out when the consumer optimizes, giving us an expression for the lambda term...

$$
\sum_{i}^{N} \beta_{i}^{1-\sigma} p_{i}^{1-\sigma}=\lambda^{\sigma-1}
$$

...that we put into (A14) to get our demand function. This is country $j$ 's demand function for goods produced by country $i$. For the sake of intuition, assume that the elasticity of substitution is greater than one. Then imports from country $i$ (defined as $\mathrm{z}_{i} p_{i}$ ) are a decreasing function of the own price and an increasing function of the price of substitutes. They are also a positive function of home income and the preference parameter beta:

(A17) $\frac{y \beta_{i}^{1-\sigma} p_{i}^{1-\sigma}}{\sum_{i}^{N} \beta_{i}^{1-\sigma} p_{i}^{1-\sigma}}=\frac{y\left(\beta_{i} p_{i}\right)^{1-\sigma}}{\sum_{i}^{N}\left(\beta_{i} p_{i}\right)^{1-\sigma}}=y_{j}\left(\frac{\beta_{i} p_{i}}{P_{j}}\right)^{1-\sigma}=z_{i} p_{i}=x_{i j}$

in which

$$
P_{j}=\left(\sum_{i}^{N}\left(\beta_{i} p_{i}\right)^{1-\sigma}\right)^{\frac{1}{1-\sigma}}
$$

To complete the derivation of the gravity model, it is first necessary to incorporate the effects of distance and tariffs. We first illustrate the Anderson and van Wincoop approach. They define a generic trade cost factor $t_{i j}$ that is multiplied by the exporter's price $p_{i}$, such that $p_{i j}=p_{i} t_{i j}$. They then note that the general equilibrium structure of the model implies

$$
y_{i}=\sum_{j} x_{i j}
$$


As they show in their equation (8),

(A20)

$$
\begin{aligned}
& y_{i}=\sum_{j}\left(\beta_{i} p_{i} t_{i j} / P_{j}\right)^{1-\sigma} y_{j} \\
& \quad=\left(\beta_{i} p_{i}\right)^{1-\sigma} \sum_{j}\left(t_{i j} / P_{j}\right)^{1-\sigma} y_{j} \\
& \left(\beta_{i} p_{i}\right)^{\sigma-1}=y_{i}^{-1} \sum_{j}\left(t_{i j} / P_{j}\right)^{1-\sigma} y_{j}
\end{aligned}
$$

They then define $\theta_{j}={ }^{y_{j}} / y^{w}$ in which $y^{w}=\sum_{i} y_{i}$. Multiplying and dividing the right hand side by $y^{w}$ allows us to express the last line of (A20) as

(A21)

$$
\left(\beta_{i} p_{i}\right)^{\sigma-1}=\frac{y^{w}}{y_{i}} \sum_{j}\left(t_{i j} / P_{j}\right)^{1-\sigma} \theta_{j}
$$

$$
\beta_{i} p_{i}=\left[\frac{y^{w}}{y_{i}} \sum_{j}\left(t_{i j} / P_{j}\right)^{1-\sigma} \theta_{j}\right]^{1 /(\sigma-1)}
$$

We simplify (A21) by defining

$$
Q_{i}=\left[\sum_{j}\left(t_{i j} / P_{j}\right)^{1-\sigma} \theta_{j}\right]^{1 /(1-\sigma)}
$$

Putting the resulting expression for $\beta_{i} p_{i}$ into (A17) generates the gravity model that we use for estimation:

(A23) $\quad x_{i j}=y_{j}\left(\frac{\left[\frac{y^{w}}{y_{i}}\right]^{1 /(\sigma-1)} Q_{i}^{-1} t_{i j}}{P_{j}}\right)^{1-\sigma}=\frac{y_{i} y_{j}}{y^{w}}\left(\frac{t_{i j}}{P_{j} Q_{i}}\right)^{1-\sigma}$ 